Article

\title{
Sustainable Market Entry Strategy under a Supply Chain Environment
}

\author{
Yanjie $W u^{1, *(\mathbb{C} \text { and Sujuan Wang }}{ }^{2}$ \\ 1 School of Economics and Management, Shanxi University, Taiyuan 030006, China \\ 2 Research Center for Management and Decision Making, Shanxi University, Taiyuan 030006, China; \\ wangsujuan-1981@163.com \\ * Correspondence: doraemontvxq@163.com
}

Citation: Wu, Y.; Wang, S. Sustainable Market Entry Strategy under a Supply Chain Environment. Sustainability 2021, 13, 3046.

https: / doi.org/10.3390/su13063046

Academic Editors: Marc A. Rosen and Anna Visvizi

Received: 30 January 2021

Accepted: 7 March 2021

Published: 10 March 2021

Publisher's Note: MDPI stays neutral with regard to jurisdictional claims in published maps and institutional affiliations.

Copyright: (c) 2021 by the authors. Licensee MDPI, Basel, Switzerland. This article is an open access article distributed under the terms and conditions of the Creative Commons Attribution (CC BY) license (https:// creativecommons.org/licenses/by/ $4.0 /)$.

\begin{abstract}
Firms routinely face the challenging decision of whether and how to enter a new market. Inspired by the practice of Chinese household appliance firms sustainably entering the rural market from the urban market, Tesla and Topshop entered the Chinese market from their own. We model a supply chain system composed of a manufacturer and a retailer to investigate entry strategies for facing a new market. These sustainable entry processes can help enterprises better achieve their own promotion and increase profits. The equilibrium solutions indicate that (1) the manufacturer's exclusive entry mode is "market development" entry, while the retailer's exclusive entry or joint entry mode can achieve "dual benefit" entry under certain conditions; and (2) both the manufacturer and the retailer prefer the joint entry mode. It is the only Nash equilibrium. Monopoly firms dominating the new market may not be profitable all the time. Appropriate competition can bring about a win-win situation. These results provide theoretical proof for the preference and rationality of the rural market entry mode in the Chinese household appliance industry and of the overseas market entry mode for international enterprises.
\end{abstract}

Keywords: supply chain; market entry; entry mode; exclusive entry; joint entry

\section{Introduction}

COVID-19 has swept the world in 2020, and trade friction between China and the United States is constantly escalating. Whether it is the Chinese mainland market or the overall international market, both are full of many uncertain factors and developing rapidly. In such a dynamic and increasingly complex business environment all around the world, more and more enterprises are constantly seeking innovation and change to adapt to new markets. Market entry has become an important step for enterprises to explore new strategic development, and the huge opportunity it contains has become an important breakthrough for domestic and foreign enterprises to improve their supply chain value. Many enterprises achieve new market entry through technological innovation, productivity improvement, product diversity, channel optimization, and geographical expansion. However, when enterprises enter the market, what kind of marketing strategy to choose has also become a key factor to determine their survival and development. Therefore, an accurate market entry decision has become one of the key factors for the stability and creation of enterprises. The entry strategy may also be important to the protection of market prosperity and the interests of whole related industries. The object of this paper is to solve the problem of how to choose an entry strategy when an enterprise faces a new market entry. Considering such a complex environment and the sustainable development of the enterprise, how should the entry strategy be deployed? Enterprises will also continue to improve with such a sustainable market entry strategy.

The household appliance industry, as an important pillar industry in the Chinese national economy, has gradually matured with the channel layout in the domestic urban market. Considering the above phenomenon, the large household appliance manufacturers 
and electronic retailers have begun to enter the rural market in China. For the rural market, household appliance manufacturers and large retailers have been racing around the field. Haier focuses on building a sales platform for the rural market through its household appliance supermarket chain brand "Gooday". Household appliance retail giants Suning and Gome also focus on the rural market layout. In 2015, Gome began to increase its number of stores on a large scale, especially in the rural market. In the first three years after its entry into the rural market, the number of stores increased by 416 , a number which is still rising. Suning is also expanding and exploring ways to enter the rural market. Through its own Suning shopping station, it extends to the lower market, carries out its rural market business in the form of service stations, and penetrates into all levels of the national market.

Looking at the world, the new American electric car Tesla was initially sold in the North American market through the direct sales mode and achieved quite good results. In 2012, Tesla officially entered the Chinese market, continuing its direct sales mode as in the North American market. Users can place orders on the Tesla website and then go to the pickup center to get the car. Different from the traditional way of selling cars through $4 \mathrm{~S}$ stores and other dealers, Tesla has adopted this direct selling mode in both the original market and the newly entered Chinese market. In addition, its marketing focuses on the construction of support services for new energy vehicles. Car consumers can bundle exclusive charging piles for installation and invest in the construction of free super-fast charging stations in a wide range. In the past few years since entering China, the sales volume of Tesla cars has continuously doubled, and the construction of the Technology Innovation Center and the Tesla Gigafactory has begun. In the era of global promotion of new energy vehicles, the timing, mode, and marketing strategy of Tesla's entry into the Chinese market have laid a solid foundation for its rapid development of new market business.

Now let's take a look at a fast fashion brand that also entered the Chinese market in 2012. Topshop is a fast fashion brand belonging to the UK's largest clothing retail group, which has a number of followers in the UK, European, and North American markets. As a brand that has been selling well in foreign markets for several years and is familiar to the vast majority of consumers, Topshop faces a bumpy road in entering the Chinese market. It opened its first store in China in 2012 and signed a contract with a third-party retailer, Shangpin.com, in 2014 to begin its expansion in the Chinese market. On its website, the brand sells clothes of the same design and style as those in the U.S. and Europe, with few customizations and matching guidelines for the Chinese market. After less than four years, in December 2018, Topshop announced a complete liquidation sale and exited the Chinese market.

Through the review of different types of enterprises, we find that different enterprises consider different opportunities in the process of market entry, enter in different ways, and adopt different marketing strategies. In view of the channel structure, which is different from that of the urban market, various major appliance manufacturers and electronic retailers penetrate the rural market through the combination of physical retail stores and online outlet stores in the Chinese household appliance industry. When Tesla entered the Chinese market, it continued the same direct store mode as in Europe and the United States for the sales of its main cars. Topshop chose to develop its business in China through a third-party retailer, copying its marketing strategy in Europe and the United States. These different entry modes and marketing strategies are also the root causes of the different results.

\subsection{Research Objective and Overview of Results}

Given the above observations and discussion from industry practice, our main research objective is to study the entry strategies that an enterprise may adopt when accessing a new market. That motivated us to explore questions such as the following: Faced with the development of a new market, how should an entry decision be made? Should either the 
manufacturer or the retailer be the exclusive one to enter the new market, or might the joint entry of both be a good choice? Facing the huge temptation of a new market, what is the most important factor when choosing which way to enter the new market? What impact will different entry strategies have on the entire market environment?

To answer the questions above, we build a supply chain system consisting of one manufacturer and one retailer, in which the manufacturer chooses to sell the product through the retailer in the original market. In the face of new markets, we study three entry modes for entering new markets (exclusive entry for the manufacturer, exclusive entry for the retailer, and joint entry), focusing on the analysis of their preferences for new market entry modes. Our analysis yields some interesting theoretical results that are in line with our real-world observations. We first show that the manufacturer and the retailer may prefer different choices when facing a new market under certain conditions. Second, contrary to conventional wisdom, we find that it is not always the optimal choice for a monopoly to enter a market exclusively and control the whole new market. Third, we find that the manufacturer always prefers "market development" exclusive entry, while the retailer can get "dual benefit" entry through joint entry. Finally, we show that all of our findings can be combined with the above Chinese appliance industry practices, Topshop's entry into the Chinese mainland market, and the Tesla's practices.

The remainder of this paper is organized as followed. The next section gives a related literature review. Section 3 constructs a game theory model consists with a manufacturer and a retailer. Section 4 presents the optimal mode of entering the market. Section 5 gives a preference analysis to illustrate our result more intuitively. Section 6 considers the case of price discrimination. Section 7 presents concluding remarks and directions for future research. All proofs are relegated to Appendix A.

\section{Literature Review}

In this section, we provide a brief review of literature related to our work. This paper involves three streams of research: competitive strategies in market entry, new technology industry entry, and the integration of market entry strategies with a sustainable supply chain environment.

Several market entry studies have focused on the relationship between market entry participants, emphasizing who will enter the new market. Scholars have investigated the competitive strategies of incumbents and entrants in the same market [1-7]. Shen and Villas-Boas [1] investigated a model of increasing demand to decide whether and when to enter the market. Considered the potential entrants, the strategic behavior will have effects on future entry. Kocak and Ozcan [2] explored how the presence of rivals affects firms' entry decisions, looking at economic and sociological explanations. The research's conclusion shows that the presence of rivals is seen as a signal that a particular market is suitable for entry. Narasimhan and Zhang [3] discussed whether an incumbent brick-and mortar retailer can deter the online entry of a pure-play e-tailer by strategically refraining from entering online. Tyagi [4] studied the effects of a new downstream retailer entry on consumer price and upstream suppliers' wholesale price. The relative strengths of the competition effect and the input cost effect may cause the profits of each incumbent downstream firm to change. On the other hand, Hauser et al. [5], Seade [6], and Amir [7] have all focused on the potential entrants' entry time, pricing, and innovation strategies under competition from existing firms. Entry into an oligopolistic industry may have some differences compared to competitive entry. In relation to that literature, this paper considers the entrants as the manufacturer and the retailer. Differing from what they mainly consider about the competition, we pay more attention to the entry decision-making of each of the two separately.

This paper can also be related to the literature on new technology industries' entry [8-27]. Yoo and Lee [8], when facing the Internet channel as a strategic choice for enterprises to enter the market, discussed how Internet channels affect the income of other channels, and analyzed the factors that influence Internet channels when entering new markets. 
Faced with the entry of a pure online retailer, Liu [9] analyzed whether existing traditional retailers increased online retail channels. These documents focus on the market entry competition strategies and strategic influences of different companies offering same-sex products (laterally competitive companies). Cawley et al. [10] discussed the mode of emerging renewable energy companies based on their time of entry. Makarevich and Kim [11] considered the impact of different contracts on firms' entry decisions under the uncertain factors of an enterprise focusing on a new market. Ozalp and Kretschmer [12] focused on the US recording industry and analyzed the interactive impact of the industry's most popular revenue-sharing contract on incumbents and competitors. Lee et al. [13] studied the software system industry and analyzed the risks and opportunities faced by complementary products in market entry. Chen et al. [14], by observing an interesting phenomenon emerging with Internet service, did research on price discrimination. The analysis showed that referral infomediaries prefer market entry with geographical exclusivity to joining retailers. Ghose et al. [15] considered the Internet's impact on optimal contracts for different entities in the supply chain. Checking whether the contracts change will impact the entry of independent and referral services. Chintakananda and Mcintyre [17] took the same approach, paying attention to the network effect on market entry. Dunning [18], Ener [19], and Gawer [21] all set the product as the market entry key point. Simonsohn [22] observed eBay, discussing whether firms have neglected competition when making entry decisions. In relation to these literatures, the home appliance industry has a close relationship with all these new technologies. Such entry strategies [21-27] may shed light on what we are focused on.

Our paper considers the integration of market entry strategies with a sustainable supply chain environment. A few examples from the literature have considered this interaction before. Lieberman et al. [28] studied entry and exit through the whole marketing environment. Markman and Waldron [29] compared the size of entrant and incumbent, building a framework for micro-entry. Pierce [30] focused on ecosystem niches, considering the big losses driven by core firm decisions. Slade et al. [31] considered stigmatized markets as the environment to be entered. Stremersch et al. [32] discussed the indirect network effect on market entry.Regional logic was said to be an influencing factor in Vedula and Corbett's [33] study. Joshi et al. [34] checked the interaction between optimal entry timing in markets and social influence. The results show that leverage, backlash, and patience are three factors for the optimal strategy predicted. Caldieraro [35] investigated horizontally different brands and vertically different products. Findings revealed that the entrant's profits interact with the incumbent, and such a competitive supply chain environment may have a strategic effect. Zachary et al. [36] empirically studied firmlevel and product-level entry timing under a supply chain environment. Further, there is research on international market entry, how the political will impact strategies of entry, and how enduring lessons impact entry timing [32-40]. These issues, although mentioned little in relation to the supply chain environment and market entry strategies, are relevant, as our research focuses on the entire sustainable supply chain environment and market entry together. Aldieri et al. [41] and Wang et al. [42] provided a good description of the sustainable natural environment, which can be extended to the sustainable market entry environment. As we can see above, this is the first time that we have studied market entry issues under a supply chain environment interacting with the overall sustainable marketing environment.

This era has endowed the whole market with richer colors, and the whole business environment has undergone unprecedented changes. Internet services, unilateral and bilateral platforms, smart home products, and other innovative elements have begun to occupy a place in the market, and these innovative elements in life are also constantly emerging. The shopping platforms for new products, the trading platforms for second-hand goods, the social platforms for sharing daily details, and the newly developed platforms for live broadcasting and delivering goods have occupied our lives. The development and integration of AI technology and the Internet also allow smart home products to gradually 
penetrate. It is precisely these that scholars should pay attention to, and they should begin to pay more attention to the impact of these innovative elements on market entry. Platform entry, Internet service, complementary hardware product access, smart home product research, and development have also become hot and difficult research fields in market entry at the present stage. Existing research also fully proves that these innovation factors not only have an impact on the market entry decision, but also determine the market entry decision-making to a large extent, which is also the research objective and focus of this paper.

Gideon et al. [43] provided a good overview of the entire market entry research field, giving a summary of the who, where, what, how, and when of market entry. Following the basic concepts and models above, we have our innovative problem of determining what is a sustainable market entry strategy under a supply chain environment.

\section{The Models}

We built a supply chain system composed of a manufacturer and a retailer, assuming both parties are risk-neutral, and considering that the manufacturer may sell products through the retailer in the original market. Facing new market opportunities, this article studies the entry mode for the new market. In this paper, the basic demand function is derived from the standard economic model. On this basis, we extend part of the problem discussed in this paper, and then get our game theory model, which is different from the original market and the new market.

We assume that both the original market and the new market demand are independent. The demand function of the original market can be expressed as

$$
D_{o}=\alpha_{o}-p_{r}
$$

where $D_{o}$ is the demand realized by the manufacturer and the retailer in the original market. $\alpha_{o}$ represents the largest potential market share in the original market. The retailer sells its products at price $p_{r}$. Alternatives between the two channels are denoted by $\theta(0 \leq \theta<1)$. Mcguire and Staelin [44] specifically set $\theta(0 \leq \theta<1)$, indicating the substitutability of the two channels in terms of changes in price. When we built the model of the original market and the new market, the current structure and game order are also obtained according to such considerations as the channel substitution rate.

Facing the new market, the manufacturer may enter exclusively, and so may the retailer. At this point, the demand realized by the manufacturer or the retailer in the new market is

$$
D_{n i}=\alpha_{n}-p_{n i}, D_{n j}=0, i, j=m, r, i \neq j
$$

It is also possible that the manufacturer and the retailer may enter the new market together, and then the demands are

$$
D_{n i}=\alpha_{n}-p_{n i}+\theta p_{n j}, i, j=m, r, i \neq j
$$

As mentioned above, $D_{n m}$ and $D_{n r}$ are demands realized by the manufacturer and the retailer in the new market. $\alpha_{n}$ represents the largest potential market share in the new market. The manufacturer and the retailer sell their products at price $p_{n i}, i=m, r$. Note that it is often assumed in the literature (e.g., Chen et al. [14], Ghose et al. [15]) that to avoid channel conflicts, more retailers will execute the same retail price $p_{n i}=p_{i}, i=m, r$ in different markets. Therefore, we assume that the retailer has the same retail price in different markets.

In the retailer channel, the wholesale price from the manufacturer is equal in both markets - that is, $w_{o}=w_{n}=w$. Note that for analytical convenience, we also suppose there is no production cost for the manufacturer, which expressed as $c=0$.

We study three types of market entry modes. MN indicates that the manufacturer enters the new market exclusively; $\mathrm{RN}$ indicates that the retailer enters the new market exclusively; and NN indicates that the manufacturer and the retailer enter the new market 
together. At the same time, in order to examine the type of new market entry, we study a no entering benchmark situation, denoted as OO. Under various modes, the decision-making, decision sequence, and decision-making goals of the manufacturer and the retailer are as follows:

Scenario OO. The manufacturer only sells products through the retailer in the original market. The decision sequence and objective function are as follows:

$$
\begin{gathered}
\text { stage } 1: \max _{w} \pi_{m}^{O O}=w D_{o} \\
\text { stage } 2: \max _{p_{r}} \pi_{r}^{O O}=\left(p_{r}-w\right)\left(D_{o}\right)
\end{gathered}
$$

Scenario MN. The manufacturer sells products through the retailer in the original market and has exclusive access to the new market. The decision sequence and objective function are as follows:

$$
\begin{gathered}
\text { stage } 1: \max _{w} \pi_{m}^{M N}=w D_{o}+p_{m} D_{n m} \\
\text { stage2 : }\left\{\begin{array}{c}
\max _{p_{r}} \pi_{r}^{M N}=\left(p_{r}-w\right)\left(D_{o}\right) \\
\max _{p_{m}} \pi_{m}^{M N}=w D_{o}+p_{m} D_{n m}
\end{array}\right.
\end{gathered}
$$

Scenario RN. The manufacturer sells products through the retailer in the original market and the retailer enters the new market exclusively. The decision sequence and objective function are as follows:

$$
\begin{gathered}
\text { stage } 1: \max _{w} \pi_{m}^{R N}=w\left(D_{o}+D_{n r}\right) \\
\text { stage2: } \max _{p_{r}} \pi_{r}^{R N}=\left(p_{r}-w\right)\left(D_{o}+D_{n r}\right)
\end{gathered}
$$

Scenario NN. The manufacturer sells products through the retailer in the original market and enters the new market together with the retailer. The decision sequence and objective function are as follows:

$$
\begin{gathered}
\text { stage } 1: \max _{w} \pi_{m}^{N N} w\left(D_{o}+D_{n r}\right)+\left(p_{m}\right)\left(D_{n m}\right) \\
\text { tage2: }\left\{\begin{array}{c}
\max _{p_{m}} \pi_{m}^{N N}=w\left(D_{o r}+D_{n r}\right)+\left(p_{m}\right)\left(D_{n m}\right) \\
\max _{p_{r}} \pi_{r}^{N N}=\left(p_{r}-w\right)\left(D_{o r}+D_{n r}\right)
\end{array}\right.
\end{gathered}
$$

Solving the games by backward induction and optimization conditions, we can get the equilibrium decision under various modes, and then get the equilibrium demand and profit. We take the model NN as an example to illustrate its derivation process. Under scenario NN, we have $\frac{\partial^{2} \pi_{r}^{N N}}{\partial p_{r}^{2}}=-4$ and $\frac{\partial^{2} \pi_{m}^{N N}}{\partial p_{m}^{2}}=-2$. It is obvious that $\pi_{m}^{N N}$ and $\pi_{r}^{N N}$ are concave functions about $p_{m}$ and $p_{r}$. For any given $w$ by the manufacturer, we can obtain the optimal retail price decision from the first order condition $p_{r}^{N N}=\frac{\left(4+\theta^{2}\right) \omega+\left(2+\theta^{2}\right) \alpha_{n}+2 \alpha_{0}}{8-\theta^{2}}$ and $p_{m}^{N N}=\frac{6 \theta \omega+(4+\theta) \alpha_{n}+\theta \alpha_{0}}{8-\theta^{2}}$. Therefore, it can be concluded that the first stage problem of the manufacturer is

$$
\pi_{m}^{N N}(w)=\frac{-2 w^{2}\left(32-14 \theta^{2}-\theta^{4}\right)+w\left(32+\theta^{4}\right) \alpha_{t}+\left(\omega\left(32+32 \theta+2 \theta^{3}+\theta^{4}\right)+2 \theta(4+\theta) \alpha_{t}\right) \alpha_{n}+\theta^{2} \alpha_{t}^{2}+(4+\theta)^{2} \alpha_{n}^{2}}{\left(8-\theta^{2}\right)^{2}}
$$

As $\frac{\partial^{2} \pi_{m}^{\mathrm{n}}}{\partial w^{2}}=\frac{-4\left(32-14 \theta^{2}-\theta^{4}\right)}{\left(8-\theta^{2}\right)^{2}}<0$, so the profit function of the manufacturer $\pi_{m}^{\mathrm{n}}(w)$ is a concave function about $w$. The manufacturer's optimal wholesale price is: $w^{N N}=$ $\frac{\left(32+32 \theta+2 \theta^{3}+\theta^{4}\right) \alpha_{n}+\left(32+\theta^{4}\right) \alpha_{o}}{4\left(32-14 \theta^{2}-\theta^{4}\right)}$. In turn, the optimal retail prices for the manufacturer, $p_{r}^{N N}=$ $\frac{\left(48+32 \theta-4 \theta^{2}+2 \theta^{3}-\theta^{4}\right) \alpha_{n}+\left(48-4 \theta^{2}-\theta^{4}\right) \alpha_{o}}{4\left(32-14 \theta^{2}-\theta^{4}\right)}$, and the retailer, $p_{m}^{N N}=\frac{\left(32+20 \theta+2 \theta^{2}-\theta^{3}\right) \alpha_{n}+\theta\left(20-\theta^{2}\right) \alpha_{o}}{2\left(32-14 \theta^{2}-\theta^{4}\right)}$, can be obtained. To ensure that all the members of the supply chain obtain positive profits 
in different markets, it is required that $D_{o}>0, D_{\mathrm{nm}}>0$, and $D_{n r}>0$. The above is equivalent to $\frac{48+32 \theta-4 \theta^{2}+2 \theta^{3}-\theta^{4}}{80-52 \theta^{2}-3 \theta^{4}}<\frac{\alpha_{0}}{\alpha_{n}}<\frac{80+32 \theta-12 \theta^{2}+2 \theta^{3}-5 \theta^{4}}{48-44 \theta^{2}+\theta^{4}}$.

The profit of the manufacturer and the retailer can be obtained (see the NN column in Table 1). In RN mode, we need to meet the conditions $\frac{3}{5}<\frac{\alpha_{0}}{\alpha_{n}}<\frac{5}{3}$ to make the profits of supply chain members in different markets positive. Further, in order to ensure that the demand of the original market and the new market is non-negative, it is necessary to meet $\frac{48+32 \theta-4 \theta^{2}+2 \theta^{3}-\theta^{4}}{80-52 \theta^{2}-3 \theta^{4}}<\frac{\alpha_{0}}{\alpha_{n}}<\frac{5}{3}$ and $0<\theta<0.823$. This means that the new market share is neither too large nor too small compared with the original market. In addition, because the manufacturer and the retailer both have their own advantages, the intensity of channel competition is within a certain range. These assumptions are in line with corporate practices.

Table 1. Equilibrium outcomes under the scenarios $\mathrm{OO}, \mathrm{MN}, \mathrm{RN}$, and NN.

\begin{tabular}{|c|c|c|c|c|}
\hline Notation & $\mathrm{OO}$ & $\mathbf{M N}$ & $\mathbf{R N}$ & $\mathbf{N N}$ \\
\hline$w$ & $\frac{\alpha_{0}}{2}$ & $\frac{\alpha_{0}}{2}$ & $\frac{\alpha_{0}+\alpha_{n}}{4}$ & $\frac{\left(32+32 \theta+2 \theta^{3}+\theta^{4}\right) \alpha_{n}+\left(32+\theta^{4}\right) \alpha_{o}}{4\left(2-\theta^{2}\right)\left(16+\theta^{2}\right)}$ \\
\hline$p_{r}=p_{n r}$ & $\frac{3 \alpha_{0}}{4}$ & $\frac{3 \alpha_{0}}{4}$ & $\frac{3\left(\alpha_{0}+\alpha_{n}\right)}{8}$ & $\frac{\left(48+32 \theta-4 \theta^{2}+2 \theta^{3}-\theta^{4}\right) \alpha_{n}+\left(48-4 \theta^{2}-\theta^{4}\right) \alpha_{o}}{4\left(2-\theta^{2}\right)\left(16+\theta^{2}\right)}$ \\
\hline$p_{m}=p_{n m}$ & & $\frac{\alpha_{n}}{2}$ & & $\frac{\left(32+20 \theta+2 \theta^{2}-\theta^{3}\right) \alpha_{n}+\theta\left(20-\theta^{2}\right) \alpha_{o}}{2\left(2-\theta^{2}\right)\left(16+\theta^{2}\right)}$ \\
\hline$\pi_{o m}$ & $\frac{\alpha_{0}^{2}}{8}$ & $\frac{\alpha_{0}^{2}}{8}$ & $\frac{\left(\alpha_{0}+\alpha_{n}\right)\left(5 \alpha_{0}-3 \alpha_{n}\right)}{32}$ & $\begin{array}{c}\frac{\left(-1536-2560 \theta-896 \theta^{2}-32 \theta^{3}-144 \theta^{4}+8 \theta^{5}+\theta^{8}\right) \alpha_{n}^{2}}{16\left(2-\theta^{2}\right)^{2}\left(16+\theta^{2}\right)^{2}} \\
+\frac{2\left(512+768 \theta-768 \theta^{2}-783 \theta^{3}-16 \theta^{4}-116 \theta^{5}-24 \theta^{6}-4 \theta^{7}-\theta^{8}\right) \alpha_{n} \alpha_{\mathrm{o}}}{16\left(2-\theta^{2}\right)^{2}\left(16+\theta^{2}\right)^{2}} \\
+\frac{\left(32+\theta^{4}\right)\left(80-52 \theta^{2}-3 \theta^{4}\right) \alpha_{\mathrm{o}}^{2}}{16\left(2-\theta^{2}\right)^{2}\left(16+\theta^{2}\right)^{2}}\end{array}$ \\
\hline$\pi_{\mathrm{o} m}$ & $\frac{\alpha_{0}^{2}}{16}$ & $\frac{\alpha_{0}^{2}}{16}$ & $\frac{\left(\alpha_{0}+\alpha_{n}\right)\left(5 \alpha_{0}-3 \alpha_{n}\right)}{64}$ & $\frac{\left(4+\theta^{2}\right)\left(\alpha_{n}+\alpha_{o}\right)\left(\left(80-52 \theta^{2}-3 \theta^{4}\right) \alpha_{o}-\left(48+32 \theta-4 \theta^{2}+2 \theta^{3}-\theta^{4}\right) \alpha_{n}\right)}{8\left(2-\theta^{2}\right)\left(16+\theta^{2}\right)^{2}}$ \\
\hline$\pi_{m}$ & $\frac{\alpha_{0}^{2}}{8}$ & $\frac{2 \alpha_{n}^{2}+\alpha_{0}^{2}}{8}$ & $\frac{\left(\alpha_{0}+\alpha_{n}\right)^{2}}{16}$ & $\frac{\left(80+64 \theta+12 \theta^{2}+4 \theta^{3}+\theta^{4}\right) \alpha_{n}^{2}+2\left(16+32 \theta+8 \theta^{2}+2 \theta^{3}+\theta^{4}\right) \alpha_{n} \alpha_{o}+\left(4+\theta^{2}\right)^{2} \alpha_{o}^{2}}{8\left(2-\theta^{2}\right)\left(16+\theta^{2}\right)}$ \\
\hline$\pi_{r}$ & $\frac{\alpha_{0}^{2}}{16}$ & $\frac{\alpha_{0}^{2}}{16}$ & $\frac{\left(\alpha_{0}+\alpha_{n}\right)^{2}}{32}$ & $\frac{\left(4+\theta^{2}\right)^{2}\left(\alpha_{n}+\alpha_{o}\right)^{2}}{2\left(16+\theta^{2}\right)^{2}}$ \\
\hline
\end{tabular}

\section{The Optimal Mode of Market Entry}

First, we compare the profits of the manufacturer and the retailer under various entry modes with the scenario of not entering a new market. The purpose is to answer whether entering a new market is necessarily beneficial.

\section{Proposition 1.}

1. $\pi_{m}^{M N}>\pi_{m}^{O O}, \pi_{\mathrm{r}}^{M N}=\pi_{\mathrm{r}}^{O O}$.

2. $\pi_{m}^{\mathrm{t}}>\pi_{m}^{O O}$ and $\pi_{\mathrm{r}}^{\mathrm{t}}>\pi_{\mathrm{r}}^{\mathrm{OO}}, t=R N, N N$.

When the manufacturer enters the new market exclusively, compared with not entering the new market, the manufacturer will get more profits, and the retailer's profit will remain unchanged. This is mainly because the manufacturer will obtain monopoly profits in the new market while maintaining profits in the original market, while the retailer still only obtain profits in the original market. When the retailer enters the new market exclusively, the manufacturer and the retailer both get more profits compared to not entering the new market. As the calculation results shown in Table $1, \frac{\partial p_{r}^{O O}}{\partial \alpha_{0}}=\frac{3}{4}>\frac{\partial \omega^{O O}}{\partial \alpha_{0}}=\frac{1}{2}$ and $\frac{\partial p_{r}^{R N}}{\partial \alpha_{0}\left(\alpha_{n}\right)}=\frac{3}{8}>\frac{\partial \omega^{R N}}{\partial \alpha_{0}\left(\alpha_{n}\right)}=\frac{1}{4}$. In other words, when the retailer enters the new market on its own, the "double marginal effect problem" can be reduced. At the same time, the entry into the new market will increase demand. Therefore, both the manufacturer and the retailer will get more benefits. When the manufacturer and the retailer enter the new market 
together, they both gain more profits. From Table 1, we have $\frac{\partial p_{r}^{O O}}{\partial \alpha_{0}}-\frac{\partial \omega^{N N}}{\partial \alpha_{0}}=\frac{4+\theta^{2}}{2\left(16+\theta^{2}\right)}$ and $\frac{\partial p_{r}^{O O}}{\partial \alpha_{n}}-\frac{\partial \omega^{N N}}{\partial \alpha_{n}}=\frac{20+16 \theta-\theta^{2}+\theta^{3}}{\left(2-\theta^{2}\right)\left(16+\theta^{2}\right)}$. Therefore, the double marginal effect becomes more serious as the market increases. At the same time, because $\frac{20+16 \theta-\theta^{2}+\theta^{3}}{\left(2-\theta^{2}\right)\left(16+\theta^{2}\right)}$ and $\frac{4+\theta^{2}}{2\left(16+\theta^{2}\right)}$ increase with the increase of $\theta$, the intensification of channel competition will aggravate the double marginal effect. Entering the new market together may exacerbate the double marginal effect, but the existence of channel competition enables the manufacturer and the retailer to set lower prices in order to increase demand and obtain higher profits.

From the above Proposition 1, exclusive entry of the manufacturer, exclusive entry of the retailer, and the joint entry all enable the manufacturer and the retailer to obtain higher profits. Next, we divide them into two types of entry based on the differences in the profits made by the manufacturer and the retailer in the original market.

Lemma 1. Under the circumstances $\pi_{o i}^{t}>\pi_{o i}^{O O}$ and $\pi_{i}^{t} \geq \pi_{i}^{O O}, i \in\{m, r\}, t \in\{M N, R N, N N\}$, after entering the new market, both the manufacturer and the retailer will obtain positive profits in the new market. However, their profits in the original market will remain unchanged or decline; that is, the profits gained after entering the new market will be sufficient for making up for the loss of its original market. The entry under this situation is called the "market development" entry mode.

Lemma 2. Under the circumstances $\pi_{o i}^{j}>\pi_{o i}^{O O}$ and $\pi_{i}^{j}>\pi_{i}^{O O}, i \in\{m, r\}, j \in\{M N, R N, N N\}$, after entering the new market, the profits will increase in both the original market and the new market for the manufacturer and the retailer. The entry under this situation is called the "dual benefit" entry mode.

Proposition 2. When the original market is direct channel:

1. The manufacturer entering the new market exclusively may see it as a "market development" entry mode.

2. The retailer enters the new markets exclusively. When $\frac{\alpha_{0}}{\alpha_{n}}>1$, it was a "dual benefit" entry mode. On the contrary, it is now a "market development" entry mode.

3. The manufacturer and the retailer enter the new market together. When $0.564<\theta$ $<0.823$ or $0<\theta<0.384$, and $\frac{\alpha_{0}}{\alpha_{n}} \leq \frac{\alpha_{0} * *}{\alpha_{n}}$, it is a "market development" entry mode; when $0<\theta<0.384$, and when $\frac{\alpha_{0}}{\alpha_{n}}>\frac{\alpha_{0}}{\alpha_{n}}$, it is a "dual benefit" entry mode. We set ${\frac{\alpha_{0}}{\alpha_{n}}}^{*}=\frac{2\left(4+\theta^{2}\right)\left(16 \theta-16+24 \theta^{2}+\theta^{3}+\theta^{4}\right)+\left(16+\theta^{2}\right) \sqrt{2\left(4+\theta^{2}\right)\left(32-32 \theta^{2}+12 \theta^{3}-6 \theta^{5}+7 \theta^{6}\right)}}{\left(8+5 \theta^{2}\right)\left(16-18 \theta^{2}+\theta^{4}\right)}$ and $\frac{\alpha_{0}}{\alpha_{n}} * *$ $\frac{-\left(512+768 \theta-768 \theta^{2}-783 \theta^{3}-16 \theta^{4}-116 \theta^{5}-24 \theta^{6}-4 \theta^{7}-\theta^{8}\right)}{\left(8+5 \theta^{2}\right)\left(64-24 \theta^{2}-20 \theta^{4}-\theta^{6}\right)}+$ $\frac{\left(2-\theta^{2}\right)\left(16+\theta^{2}\right)-\sqrt{2\left(512+1024 \theta+672 \theta^{2}+96 \theta^{3}+96 \theta^{4}+120 \theta^{5}+2 \theta^{6}+4 \theta^{7}+3 \theta^{8}\right)}}{\left(8+5 \theta^{2}\right)\left(64-24 \theta^{2}-20 \theta^{4}-\theta^{6}\right)}$ $\left(8+5 \theta^{2}\right)\left(64-24 \theta^{2}-20 \theta^{4}-\theta^{6}\right)$

From Proposition 2, both the retailer's exclusive entry and the two firms' joint entry into the new market mode can achieve "dual benefit" entry. The manufacturer's exclusive entry can only achieve "market development" entry. Compared with the manufacturer's exclusive entry, the retailer's exclusive entry and the joint entry of both firms have more advantages. Specifically, when the original market is larger than the potential share of the new market, the retailer's exclusive entry is a "dual benefit" entry mode, and vice versa is a "market development" entry mode. When the manufacturer and the retailer enter together, the channel competition is not fierce. When the potential market share is small, it is the "dual benefit" entry mode (see Figures 1 and 2). If the potential market share of the new market is large, it is the "market development" entry mode; if the channel competition is fierce, regardless of the new potential market share, it is a "market development type" entry mode. 


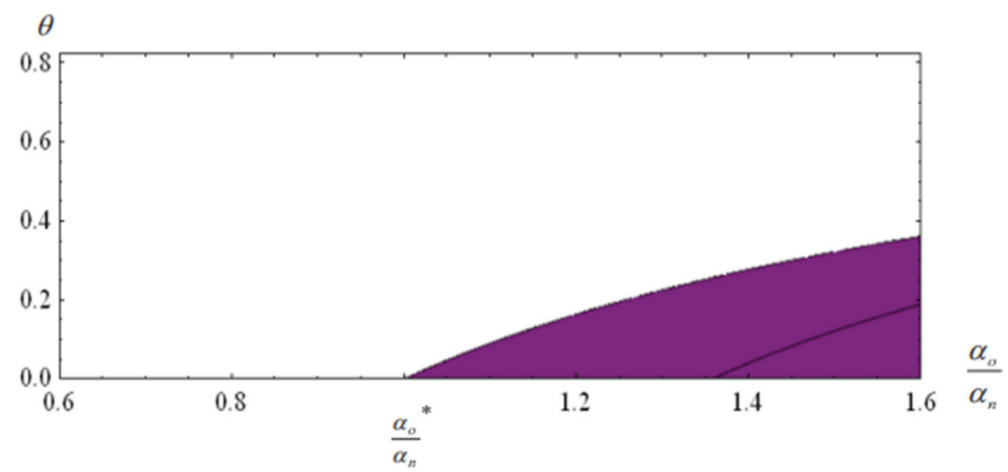

Figure 1. The retailer's profit dominance region for the NN model in the original market: $\pi_{o r}^{N N}>\pi_{o r}^{O O}$ (the shaded area).

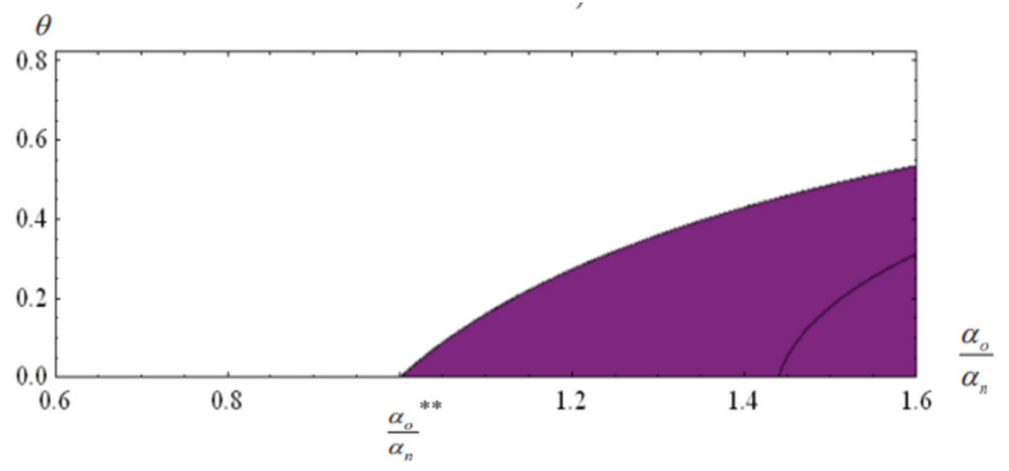

Figure 2. The manufacturer's profit dominance region for the NN model in the original market: $\pi_{o m}^{N N}>\pi_{o m}^{O O}$ (the shaded area).

\section{Preference Analysis of New Market Entry Modes}

In this section, we answer the following questions based on the above conclusions: (1) In which mode does the manufacturer prefer to enter the new market? (2) In which mode does the retailer prefer to enter the new market? (3) Which entry mode is market equilibrium? We compare the profits of the manufacturer and the retailer under different modes, then get the following propositions.

\section{Proposition 3.}

1. $\pi_{m}^{N N}>\pi_{m}^{M N}>\pi_{m}^{\mathrm{RN}}$

2. $\quad \pi_{r}^{\mathrm{NN}}>\pi_{r}^{\mathrm{RN}}>\pi_{r}^{M N}$

Whether the manufacturer or the retailer enter new markets exclusively or jointly, they will increase demand. Different entry modes bring different increases in demand. Generally speaking, the joint entry mode should bring more demand increase than exclusive entry, because consumers in the new market may have more choices. At the same time, channel competition will intensify the double marginal effect of the joint entry mode. Therefore, the manufacturer and the retailer have to weigh the impact of increased demand and the double marginal effect on profits. When only considering the exclusive entry mode, it can be seen from Proposition 3 that both the manufacturer and the retailer are willing to enter the new market just by themselves. This is because any party that enters alone may enjoy the monopoly profits of the new market. When considering the joint entry mode, both the manufacturer and the retailer are willing to choose joint entry.

This conclusion is counter-intuitive, because one might think that any firm wants to dominate the market and obtain monopoly profits. The above proposition tells us that both the manufacturer and the retailer are willing to compete in the new market. The reason 
is that when entering a new market together, competition will bring about a decrease in prices, which in turn will increase demand. The advantage of high demand versus the disadvantage of double marginal effect will increase profits.

Proposition 3 analyzes preference for entry mode from the perspective of the manufacturer and the retailer. What kind of entry mode will become the market entry equilibrium? We will conclude on this issue in the following proposition. To study the entry equilibrium, we study the following market entry decision game, as shown in Table 2. In this game the manufacturer and the retailer simultaneously decide whether to enter a new market.

Table 2. The market entry game.

\begin{tabular}{ccc}
\hline Notation & $\mathbf{M}$ & $\mathbf{M}$ \\
\hline $\mathrm{R}$ & $\left(\pi_{m}^{O O}, \pi_{r}^{O O}\right)$ & $\left(\pi_{m}^{M N}, \pi_{r}^{M N}\right)$ \\
$\mathrm{R}$ & $\left(\pi_{m}^{R N}, \pi_{r}^{R N}\right)$ & $\left(\pi_{m}^{N N}, \pi_{r}^{N N}\right)$ \\
\hline
\end{tabular}

Proposition 4. The joint entry mode (NN) is the only Nash equilibrium.

Propositions 3 and 4 show that entering a new market together is the only Nash equilibrium strategy. This conclusion is consistent with the practice of the Chinese household appliance industry in developing the rural market. Surrounding the competition in the rural markets, household appliance companies and large channel retailers are racing to occupy the rural market.

Whether an enterprise chooses to enter a new market alone or together with other participants according to its own conditions, or through opening up new channels to enter a new market, or through different product strategies to enter a new market, these are all strategies and methods to consider entering the market. Usually, we think that retailers or manufacturers can be selected to enter a new market independently, so as to maximize the profits and advantages brought by the monopoly market. Will such one-party dominance bring the greatest benefit to the enterprise? From the results of the calculation, we can see different results. On the other hand, when some competitors enter a new market together, and when manufacturers and retailers enter a new market together, the double competition will lead to a certain degree of price decline, improve the quality of products and services, and increase the desire of consumers to purchase. The resulting increased sales will bring greater benefits to both sides of the business. Uniqlo, a Japanese fast fashion brand, has penetrated into the Chinese market by setting up a large number of direct-sale stores, and has meanwhile opened an official flagship store on a large e-commerce website. The stores are operated and managed by the brand itself; the initiative is better in its own hands. Uniqlo has become the main force in China's fast garment consumption industry, and its rapid penetration with the joint entry strategy and expansion also provide a certain reference for other brands to enter. By contrast, as mentioned above, the British fast fashion brand Topshop chose to enter the Chinese market through a completely unknown thirdparty retail platform, Shangpin.com. Instead of joint entry, setting up a large number of its own direct stores, it left the brand management and operation exclusively to the third-party retail platform. In this way, they lost the understanding and management of the market to a certain extent, and such an entry strategy also led to their failure to exit the Chinese market in the end. Only by choosing appropriate entry strategies suitable for the development of enterprises can they better adapt to and profit from a new market.

\section{Extensions: Discriminatory Pricing}

In the basic model, we assume that the manufacturer and the retailer cannot set discriminatory prices - that is, wholesale prices and retail prices are the same in different markets. In this section, we relax this assumption and allow the manufacturer and the retailer to discriminate in pricing. This section examines the impact of discriminatory prices on the above conclusions. Discriminating pricing in different markets will affect 
the retailer's exclusive entry and joint entry mode in the basic model. The calculated equilibrium price and profit are shown in Table 3.

Table 3. The optimal decisions and profits in RN and NN under discriminatory pricing.

\begin{tabular}{ccc}
\hline Notation & RN & NN \\
\hline$w_{o}$ & $\frac{\alpha_{0}}{2}$ & $\frac{\alpha_{0}}{2}$ \\
\hline$w_{n}$ & $\frac{\alpha_{n}}{2}$ & $\frac{\left(8+\theta^{3}\right) \alpha_{n}}{2(1-\theta)\left(8+\theta^{2}\right)}$ \\
\hline$p_{r}$ & $\frac{3 \alpha_{0}}{4}$ & $\frac{3 \alpha_{0}}{4}$ \\
\hline$p_{r n}$ & $\frac{3 \alpha_{n}}{4}$ & $\frac{\left(12-4 \theta+2 \theta^{2}-\theta^{3}\right) \alpha_{n}}{2(1-\theta)\left(8+\theta^{2}\right)}$ \\
\hline$p_{m}$ & & $\frac{(4-\theta)(2+\theta) \alpha_{n}}{2(1-\theta)\left(8+\theta^{2}\right)}$ \\
\hline$\pi_{o m}$ & $\frac{\alpha_{0}^{2}}{8}$ & $\frac{\alpha_{0}^{2}}{8}$ \\
\hline$\pi_{o r}$ & $\frac{\alpha_{0}^{2}}{16}$ & $\frac{\alpha_{0}^{2}}{16}$ \\
\hline$\pi_{m}=p_{n m}$ & $\frac{\alpha_{0}^{2}+\alpha_{n}^{2}}{8}$ & $\frac{2\left(12+4 \theta+\theta^{2}+\theta^{3}\right) \alpha_{n}^{2}+(1-\theta)\left(8+\theta^{2}\right) \alpha_{0}^{2}}{8(1-\theta)\left(8+\theta^{2}\right)}$ \\
\hline$\pi_{r}$ & $\frac{\alpha_{0}^{2}+\alpha_{n}^{2}}{16}$ & $\frac{16\left(2+\theta^{2}\right)^{2} \alpha_{n}^{2}+\left(8+\theta^{2}\right)^{2} \alpha_{0}^{2}}{16\left(8+\theta^{2}\right)^{2}}$ \\
\hline
\end{tabular}

Proposition 5. When the original market is dual channel, DEE is the best mode for choosing to enter the new market together for both the manufacturer and the retailer.

1. $\pi_{m}^{t}>\pi_{m}^{O O}, \pi_{r}^{t}>\pi_{r}^{O O} ; \pi_{o m}^{t}=\pi_{o m}^{O O}, \pi_{o r}^{t}=\pi_{o r}^{O O} . t \in\{R N, N N\}$

2. $\quad \pi_{m}^{N N}>\pi_{m}^{M N}>\pi_{m}^{R N}, \pi_{r}^{N N}>\pi_{r}^{R N}>\pi_{r}^{M N}$. The joint entry mode (NN) is the only Nash equilibrium.

Results from Proposition 5 show that when the manufacturer and the retailer can implement discriminatory pricing strategies, all entry modes are "market development" entry. The remaining conclusions remain unchanged.

\section{Conclusions}

Technological innovation and the growing complexity of globalization mean the whole business environment is constantly in a state of dynamic change. Even the problem of market entry is getting more and more attention from all kinds of enterprises around the world. Sustainable market entry has also received a lot of attention from researchers in a number of areas, especially regarding the supply chain environment. In this study, by analyzing a game-theoretic model that explicitly captures the differences under the supply chain environment, we have investigated the choice of new market entry. We plan an entire sustainable business path for companies by discussing their entry strategies for new markets. The conclusions of this paper are instructive for different types of enterprises to choose strategies in new market entry. Next, we will summarize the main conclusions and management insights of this article.

We first investigate the entry mode and entry type of new market, and by comparing the profits of supply chain members under various entry modes and non-entry scenarios, we conclude that any entry mode will increase the profits of supply chain members. However, the retailer entering alone or both parties entering together can achieve "dual benefit" entry, while the manufacturer entering alone can only be "market development" entry. Next, we examine the preference of supply chain members to choose an entry mode with market entry equilibrium. We conclude that both the manufacturer and the retailer are willing to choose joint entry, and their mode is the only market entry equilibrium. The important management insight is this: the monopoly profit obtained by the enterprise monopolizing the market is not necessarily profit; proper competition can bring about 
a win-win situation. As a result, home appliance manufacturers and retailers are racing to open up the rural market. These enterprises are also constantly realizing their own sustainable development through the method of market entry.

In our model, we consider that in the original market, the manufacturer sells through the retailer. In the practice of the firm, the original market may be sold directly by the manufacturer, or the manufacturer not only sells directly, but also sells through the retailer. It can be further extended to the latter two scenarios, which we will analyze in detail in another article. At the same time, we assume that the demands of the new market and the old market are independent, so we can further analyze the market entry decision when the old market affects the new market. In addition, this paper studies certain market demand, which can be further extended to random demand. The research object of this paper is a supply chain system composed of a manufacturer and a retailer. In a competitive environment, such as manufacturer competition or retailer competition and supply chain competition, studying this problem will lead in a meaningful direction.

Author Contributions: Conceptualization, Y.W. and S.W.; methodology, Y.W.; software, Y.W.; validation, Y.W.; writing —original draft preparation, Y.W.; writing—review and editing, Y.W. and S.W.; visualization, Y.W.; supervision, Y.W. and S.W. All authors have read and agreed to the published version of the manuscript.

Funding: This research received no external funding.

Institutional Review Board Statement: Not applicable.

Informed Consent Statement: Not applicable.

Data Availability Statement: Not applicable.

Conflicts of Interest: The authors declare no conflict of interest.

\section{Appendix A.}

Appendix A.1. Proof of Proposition 1

(1) From Table 1, we can clearly get the following conclusions: $\pi_{m}^{N N}>\pi_{m}^{O O}$ and $\pi_{r}^{M N}=\pi_{r}^{O O}$.

(2) Continue to obtain the data in Table 1 that if $\pi_{m}^{R N}>\pi_{m}^{O O}$, if and only if $\sqrt{\pi_{m}^{R N}}-\sqrt{\pi_{m}^{O O}}=\frac{\sqrt{2} \alpha_{n}+(\sqrt{2}-2) \alpha_{o}}{4 \sqrt{2}}>0 \Leftrightarrow \frac{\alpha_{o}}{\alpha_{n}}<\sqrt{2}+1$. Same goes for if $\pi_{r}^{R N}>\pi_{r}^{O O}$, if and only if $\sqrt{\pi_{r}^{R N}}-\sqrt{\pi_{r}^{O O}}=\frac{\alpha_{n}+(1-\sqrt{2}) \alpha_{o}}{4 \sqrt{2}}>0 \Leftrightarrow \frac{\alpha_{o}}{\alpha_{n}}<\sqrt{2}+1$. As $\frac{\alpha_{o}}{\alpha_{n}}<\frac{5}{3}<\sqrt{2}+1$, so the condition $\frac{\alpha_{o}}{\alpha_{n}}<\sqrt{2}+1$ is satisfied. It can also be obtained from Table 1 that if $\pi_{r}^{N N}>\pi_{r}^{O O}$, if and only if $\sqrt{\pi_{r}^{N N}}-\sqrt{\pi_{r}^{O O}}=\frac{4\left(4+\theta^{2}\right) \alpha_{n}-\left(\sqrt{2}\left(16+\theta^{2}\right)-4\left(4+\theta^{2}\right)\right) \alpha_{o}}{4 \sqrt{2}\left(16+\theta^{2}\right)}>0 \Leftrightarrow \frac{\alpha_{0}}{\alpha_{n}}<\frac{4\left(4+\theta^{2}\right)}{4 \sqrt{2}\left(16+\theta^{2}\right)-4\left(4+\theta^{2}\right)}$. It is also because $\frac{4\left(4+\theta^{2}\right)}{4 \sqrt{2}\left(16+\theta^{2}\right)-4\left(4+\theta^{2}\right)}-\frac{5}{3}>0$, so $\pi_{r}^{N N}>\pi_{r}^{O O}$. When $\pi_{m}^{N N}>\pi_{m}^{O O}$, if and only if $\pi_{m}^{N N}-\pi_{m}^{O O}=\frac{f_{1}\left(\frac{\alpha_{o}}{\alpha_{n}}\right)}{8\left(2-\theta^{2}\right)\left(16+\theta^{2}\right)}>0$. Among them, $f_{1}\left(\frac{\alpha_{o}}{\alpha_{n}}\right)=\left(80+64 \theta+12 \theta^{2}+\right.$ $\left.4 \theta^{3}+\theta^{4}\right)+2\left(16+32 \theta+8 \theta^{2}+2 \theta^{3}+\theta^{4}\right) \frac{\alpha_{0}}{\alpha_{n}}-2\left(8-11 \theta^{2}-\theta^{4}\right)\left(\frac{\alpha_{o}}{\alpha_{n}}\right)^{2}$. There is no solution on the interval $\frac{48+32 \theta-4 \theta^{2}+2 \theta^{3}-\theta^{4}}{80-52 \theta^{2}-3 \theta^{4}}<\frac{\alpha_{0}}{\alpha_{n}}<\frac{5}{3}$ and $0<\theta<0.823$. According to the nature of the quadratic equation in one unknown, if $8-11 \theta^{2}-\theta^{4}>0, f_{1}\left(\frac{\alpha_{o}}{\alpha_{n}}\right)>0$ otherwise $f_{1}\left(\frac{\alpha_{o}}{\alpha_{n}}\right)<0$. That is when $0<\theta<0.827$, we have $\pi_{m}^{N N}>\pi_{m}^{O O}$, otherwise $\pi_{m}^{N N}<\pi_{m}^{O O}$. We also have $0<\theta<0.823<0.827$, so we got the proof $\pi_{m}^{N N}>\pi_{m}^{O O}$. This completes the proof.

Appendix A.2. Proof of Proposition 2

We can obtain from Table 1 that $\pi_{o i}^{M N}=\pi_{o i}^{O O}, i \in\{m, r\} ., \pi_{m}^{M N}>\pi_{m}^{O O}$, and $\pi_{r}^{M N}=$ $\pi_{r}^{O O}$. Thus, the result is obvious.

Continue to obtain the data in Table 1, and we have $\pi_{o i}^{M N}>\pi_{o i}^{O O}, i \in\{m, r\}$. The result can also be conducted form Proposition 1 that $\pi_{i}^{R N}>\pi_{i}^{O O}, i \in\{m, r\}$. 
From Proposition 1, we got $\pi_{r}^{M N}>\pi_{r}^{O O}$ and $\pi_{m}^{M N}=\pi_{m}^{O O}$. Now we need to consider the changes in profits in the original market after the manufacturer and the retailer enter the new market together. Let us first analyze the changes in retailers' profits in the old market. It is obvious from Table $1, \pi_{o r}^{N N}-\pi_{o r}^{O O}=\frac{f_{2}\left(\frac{\alpha_{o}}{\alpha_{n}}\right)}{16\left(2-\theta^{2}\right)\left(16+\theta^{2}\right)}$. Among them $f_{2}\left(\frac{\alpha_{o}}{\alpha_{n}}\right)=$ $4\left(64-64 \theta-80 \theta^{2}-20 \theta^{3}-28 \theta^{4}-\theta^{5}-\theta^{6}\right) \frac{\alpha_{o}}{\alpha_{n}}+\left(128-64 \theta^{2}-98 \theta^{4}-5 \theta^{6}\right)\left(\frac{\alpha_{o}}{\alpha_{n}}\right)^{2}-(384+$ $\left.256 \theta+64 \theta^{2}+80 \theta^{3}-16 \theta^{4}+4 \theta^{5}-2 \theta^{6}\right)$. When $\theta>0.384, f_{2}\left(\frac{\alpha_{o}}{\alpha_{n}}\right)$ has no solution. According to the nature of the quadratic equation in one unknown, if $128-64 \theta^{2}-98 \theta^{4}-5 \theta^{6}>0$ that is $0<\theta<0.921, f_{2}\left(\frac{\alpha_{0}}{\alpha_{n}}\right)<0$. If $128-64 \theta^{2}-98 \theta^{4}-5 \theta^{6}<0$ that is $0.921<\theta<1$, $f_{2}\left(\frac{\alpha_{o}}{\alpha_{n}}\right)>0$. It also as $0<\theta<0.823$ that we got when $0.384<\theta<823, f_{2}\left(\frac{\alpha_{o}}{\alpha_{n}}\right)<0$. When $0<\theta<0.384,128-128 \theta-168 \theta^{2}-88 \theta^{3}-36 \theta^{4}-12 \theta^{5}-\theta^{6}-\theta^{7}>0, f_{2}\left(\frac{\alpha_{o}}{\alpha_{n}}\right)$ has one root $\frac{\alpha_{0}}{\alpha_{n}}=\frac{2\left(4+\theta^{2}\right)\left(16 \theta-16+24 \theta^{2}+\theta^{3}+\theta^{4}\right)+\left(16+\theta^{2}\right) \sqrt{2\left(4+\theta^{2}\right)\left(32-32 \theta^{2}+12 \theta^{3}-6 \theta^{5}+7 \theta^{6}\right)}}{\left(8+5 \theta^{2}\right)\left(16-18 \theta^{2}+\theta^{4}\right)}$. According to the nature of the quadratic equation in one unknown, if $0<\theta<0.384$ and $\frac{\alpha_{0}}{\alpha_{n}}<\frac{\alpha_{0}}{\alpha_{n}}$, $f_{2}\left(\frac{\alpha_{o}}{\alpha_{n}}\right)<0$. Thus if $0.384<\theta<823$ or $0<\theta<0.823$ and when $\frac{\alpha_{o}}{\alpha_{n}}<\frac{\alpha_{0}{ }^{*}}{\alpha_{n}}, \pi_{o r}^{N N}<\pi_{o r}^{O O}$; if $0<\theta<0.384$ and when $\frac{\alpha_{0}}{\alpha_{n}} \geq \frac{\alpha_{0} *}{\alpha_{n}}, \pi_{o r}^{N N}>\pi_{o r}^{O O}$. We can also get, $\pi_{o m}^{N N}-\pi_{o m}^{O O}=$ $\frac{f_{3}\left(\frac{\alpha_{o}}{\mu_{n}}\right)}{\left(2-\theta^{2}\right)^{2}\left(16+\theta^{2}\right)^{2}}$. Among it,

$$
\begin{gathered}
f_{3}\left(\frac{\alpha_{o}}{\alpha_{n}}\right)=2\left(512+768 \theta-768 \theta^{2}-784 \theta^{3}-16 \theta^{4}-116 \theta^{5}-24 \theta^{6}-4 \theta^{7}-\theta^{8}\right) \frac{\alpha_{o}}{\alpha_{n}}+ \\
\left(512+128 \theta^{2}-280 \theta^{4}-108 \theta^{6}-5 \theta^{8}\right)\left(\frac{\alpha_{o}}{\alpha_{n}}\right)^{2}
\end{gathered}
$$

$-\left(1536+256 \theta+896 \theta^{2}+32 \theta^{3}+144 \theta^{4}-8 \theta^{5}-\theta^{8}\right)$. When $\theta>0.564, f_{3}\left(\frac{\alpha_{o}}{\alpha_{n}}\right)$ has no solution. According to the nature of the quadratic equation in one unknown, $f_{3}\left(\frac{\alpha_{0}}{\alpha_{n}}\right)<0$; when $0<\theta<0.564, f_{3}\left(\frac{\alpha_{o}}{\alpha_{n}}\right)$ has only one root $\frac{\alpha_{o}}{\alpha_{n}} * *=\frac{-\left(512+768 \theta-768 \theta^{2}-783 \theta^{3}-16 \theta^{4}-116^{5}-24 \theta^{6}-4 \theta^{7}-\theta^{8}\right)}{\left(8+5 \theta^{2}\right)\left(64-24 \theta^{2}-20 \theta^{4}-\theta^{6}\right)}$ $+\frac{\left(2-\theta^{2}\right)\left(16+\theta^{2}\right)-\sqrt{2\left(512+1024 \theta+672 \theta^{2}+96 \theta^{3}+96 \theta^{4}+120 \theta^{5}+2 \theta^{6}+4 \theta^{7}+3 \theta^{8}\right)}}{\left(8+5 \theta^{2}\right)\left(64-24 \theta^{2}-20 \theta^{4}-\theta^{6}\right)}$. According to the nature of the quadratic equation in one unknown, if $0.564<\theta<0.823$ and $\frac{\alpha_{o}}{\alpha_{n}}<\frac{\alpha_{0}}{\alpha_{n}} * f_{3}\left(\frac{\alpha_{o}}{\alpha_{n}}\right)<0$. Thus if $0.564<\theta<0.823$ or $0<\theta<0.564$ and when $\frac{\alpha_{o}}{\alpha_{n}}<\frac{\alpha_{o} * *}{\alpha_{n}}, \pi_{o m}^{N N}<\pi_{o m}^{O O}$ and $\pi_{m}^{N N}>\pi_{m}^{O O}$. When $0<\theta<0.564$ and when $\frac{\alpha_{o}}{\alpha_{n}} \geq \frac{\alpha_{0} * *}{\alpha_{n}}, \pi_{o r}^{N N}>\pi_{o r}^{O O}$ and $\pi_{m}^{N N}>\pi_{m}^{O O}$.

\section{Appendix A.3. Proof of Proposition 3}

(1) It can be obtained from Table 1 that $\pi_{m}^{M N}-\pi_{m}^{R N}=\frac{2 \alpha_{n}^{2}+\left(\alpha_{n}-\alpha_{o}\right)^{2}}{16}>0$. The same goes for that when $\pi_{m}^{N N}>\pi_{m}^{N N}$, if and only if $\pi_{m}^{N N}-\pi_{m}^{M N}=\frac{f_{4}\left(\frac{\alpha_{o}}{\alpha_{n}}\right)}{8\left(2-\theta^{2}\right)\left(16+\theta^{2}\right)}>0$. Among them, $f_{4}\left(\frac{\alpha_{o}}{\alpha_{n}}\right)=\left(16+64 \theta+40 \theta^{2}+4 \theta^{3}+3 \theta^{4}\right)+2\left(16+32 \theta+8 \theta^{2}+2 \theta^{3}+\theta^{4}\right) \frac{\alpha_{o}}{\alpha_{n}}-2(8-$ $\left.11 \theta^{2}-\theta^{4}\right) \frac{\alpha_{0}}{\alpha_{n}}$. Thus, there is no solution on the interval $\frac{48+32 \theta-4 \theta^{2}+2 \theta^{3}-\theta^{4}}{80-52 \theta^{2}-3 \theta^{4}}<\frac{\alpha_{o}}{\alpha_{n}}<\frac{5}{3}$. According to the nature of the quadratic equation in one unknown, if $0<\theta<0.827$ and $8-11 \theta^{2}-\theta^{4}>0, f_{4}\left(\frac{\alpha_{o}}{\alpha_{n}}\right)>0$. It is obvious that $\pi_{m}^{N N}>\pi_{m}^{M N}$.

(2) From Table 1, we have $\pi_{r}^{R N}-\pi_{r}^{M N}=\pi_{r}^{R N}-\pi_{r}^{O O}$. The result can also be conducted form Proposition 1 that $\pi_{r}^{R N}-\pi_{r}^{M N}>0$; therefore, we got the proof. At the same time, when $\pi_{r}^{N N}>\pi_{r}^{R N}$, if and only if $\sqrt{\pi_{r}^{N N}}-\sqrt{\pi_{r}^{R N}}=\frac{3 \theta^{2}\left(\alpha_{o}+\alpha_{o}\right)}{4 \sqrt{2}\left(16+\theta^{2}\right)}>0$, so we have $\pi_{r}^{N N}>$ $\pi_{r}^{R N}$. This completes the proof.

\section{Appendix A.4. Proof of Proposition 4}

We obtain from Proposition 3 that $\pi_{r}^{N N}>\pi_{r}^{M N}$. After calculation from Table 1 we have $\pi_{m}^{N N}-\pi_{m}^{R N}=\frac{\left(128+128 \theta+38 \theta^{2}+8 \theta^{3}+3 \theta^{4}\right) \alpha_{n}^{2}+2 \theta\left(64+30 \theta+4 \theta^{2}+3 \theta^{3}\right) \alpha_{n} \alpha_{0}+3 \theta^{3}\left(10+\theta^{2}\right) \alpha_{o}^{2}}{16\left(2-\theta^{2}\right)\left(16+\theta^{2}\right)}>0$. Theereefore, we have $\pi_{m}^{N N}>\pi_{m}^{R N}$. The joint entry mode (NN) is the only Nash equilibrium.

This completes the proof. 


\section{Appendix A.5. Proof of Proposition 5}

We obtain from Tables 1 and $3, \pi_{m}^{M N}-\pi_{m}^{R N}=\frac{\alpha_{n}^{2}}{4}>0, \pi_{m}^{N N}-\pi_{m}^{M N}=\frac{2+6 \theta+\theta^{3}}{2(1-\theta)\left(8+\theta^{2}\right)}>0$. Therefore, we have $\pi_{m}^{N N}>\pi_{m}^{M N}>\pi_{m}^{R N}$. Still from Tables 1 and 3, $\pi_{r}^{R N}-\pi_{r}^{M N}=\frac{\alpha_{n}^{2}}{16}>0$, $\pi_{r}^{N N}-\pi_{r}^{R N}=\frac{3 \theta^{2}\left(16+5 \theta^{2}\right) \alpha_{n}^{2}}{16\left(8+\theta^{2}\right)^{2}}>0$. We got $\pi_{r}^{N N}>\pi_{r}^{R N}>\pi_{r}^{M N}$.

Above all, we have $\pi_{r}^{N N}>\pi_{r}^{M N}$ and $\pi_{m}^{N N}>\pi_{m}^{R N}$. The joint entry mode (NN) is the only Nash equilibrium.

\section{References}

1. Shen, Q.; Villas-Boas, J.M. Strategic Entry Before Demand Takes Off. Manag. Sci. 2010, 56, 1259-1271. [CrossRef]

2. Koçak, Ö.; Özcan, S. How does rivals' presence affect firms' decision to enter new markets? Manag. Sci. 2013, 59, $2586-2603$. [CrossRef]

3. Narasimhan, C.; Zhang, Z.J. Market Entry Strategy Under Firm Heterogeneity and Asymmetric Payoffs. Mark. Sci. 2000, 19, 313-327. [CrossRef]

4. Tyagi, R.K. On the effects of downstream entry. Manag. Sci. 1999, 45, 59-73. [CrossRef]

5. Hauser, J.R.; Shugan, S.M. Defensive marketing strategies. Mark. Sci. 2008, 27, 88-110. [CrossRef]

6. Seade, J. On the effects of entry. Econometrica 1980, 48, 479-489. [CrossRef]

7. Amir, R.; Lambson, V.E. On the effects of entry in Cournot markets. Rev. Econ. Stud. 2000, 67, 235-254. [CrossRef]

8. Yoo, W.S.; Lee, E. Internet Channel Entry: A Strategic Analysis of Mixed Channel Structures. Mark. Sci. 2011, 30, 29-41. [CrossRef]

9. Liu, Y.; Gupta, S.; Zhang, Z.J. Note on Self-Restraint as an Online Entry-Deterrence Strategy. Manag. Sci. 2006, 52, 1799-1809. [CrossRef]

10. Mac Cawley, A.F.; Sevil, Á.; Vassolo, R.S.; Sepúlveda Vargas, J.I. Entry-Timing Advantages in Renewable Natural Resources Industries. J. Manag. Stud. 2019, 56, 1482-1512. [CrossRef]

11. Makarevich, A.; Kim, Y. Following in partners' footsteps: An uncertainty-reduction perspective on firms' choice of new markets. J. Manag. Stud. 2019, 56, 1314-1344. [CrossRef]

12. Ozalp, H.; Kretschmer, T. Follow the crowd or follow the trailblazer? The differential role of firm experience in product entry decisions in the US video game industry. J. Manag. Stud. 2019, 56, 1452-1481. [CrossRef]

13. Lee, C.H.; Venkatraman, N.; Tanriverdi, H.; Iyer, B. Complementarity-based hyper competition in the software industry: Theory and empirical test, 1990-2002. Strateg. Manag. J. 2010, 31, 1431-1456. [CrossRef]

14. Chen, Y.; Iyer, G.; Padmanabhan, V. Referral infomediaries. Mark. Sci. 2002, 21, 412-434. [CrossRef]

15. Ghose, A.; Mukhopadhyay, T.; Rajan, U. The Impact of Internet Referral Services on a Supply Chain. Inf. Syst. Res. 2007, 18, 300-319. [CrossRef]

16. Boeker, W. Executive migration and strategic change: The effect of top manager movement on product-market entry. Admin. Sci. Q. 1997, 64, 213-236. [CrossRef]

17. Chintakananda, A.; McIntyre, D.P. Market entry in the presence of network effects: A real options perspective. J. Manag. 2014, 40, 1535-1557. [CrossRef]

18. Dunning, J.H. Location and the multinational enterprise: A neglected factor? J. Int. Bus. Stud. 1998, 29, 45-66. [CrossRef]

19. Ener, H. Do prior experiences of top executives enable or hinder product market entry? J. Manag. Stud. 2019, 56, 1345-1376. [CrossRef]

20. Filatotchev, I.; Strange, R.; Piesse, J.; Yung-Chih, L. FDI by firms from newly industrialized economies in emerging markets: Corporate governance, entry mode and location. J. Int. Bus. Stud. 2007, 38, 556-572. [CrossRef]

21. Gawer, A.; Henderson, R. Platform Owner Entry and Innovation in Complementary Markets: Evidence from Intel. J. Econ. Manag. Strat. 2007, 16, 1-34. [CrossRef]

22. Simonsohn, U. eBay's Crowded Evenings: Competition Neglect in Market Entry Decisions. SSRN Electron. J. 2010, 56, 1060-1073.

23. Horn, J.T.; Lovallo, D.P.; Viguerie, S.P. Beating the odds in market entry. McKinsey Q. 2005, 4, 35-45.

24. Javalgi, R.R.G.; Deligonul, S.; Dixit, A.; Cavusgil, S.T. International market reentry: A review and research framework. Int. Bus. Rev. 2011, 20, 377-393. [CrossRef]

25. Lampert, C.M.; Kim, M.; Hubbard, T.D.; Roy, R.; Leckie, G. Fearlessly swimming upstream to risky waters: The role of geographic entry in innovation. J. Manag. Stud. 2019, 56, 1377-1413. [CrossRef]

26. Wu, C.; Huang, F.; Huang, C.; Zhang, H. Entry Mode, Market Selection, and Innovation Performance. Sustainability 2018, 10, 4222. [CrossRef]

27. Wu, C.; Bo, S.; Wan, X.; Ji, M.; Chen, M.; Zhang, S. Does the Choice of IJV under Institutional Duality Promote the Innovation Performance of Chinese Manufacturing Firms? Evidence from Listed Chinese Manufacturing Companies. Sustainability 2020, 12, 6869. [CrossRef]

28. Lieberman, M.B.; Lee, G.K.; Folta, T.B. Entry, exit, and the potential for resource redeployment. Strat. Manag. J. 2016, 38, 526-544. [CrossRef]

29. Markman, G.D.; Waldron, T.L. Small Entrants and Large Incumbents: A Framework of Micro Entry. Acad. Manag. Perspect. 2014, 28, 179-197. [CrossRef] 
30. Pierce, L. Big losses in ecosystem niches: How core firm decisions drive complementary product shakeouts. Strat. Manag. J. 2009, 30, 323-347. [CrossRef]

31. Slade Shantz, A.; Fischer, E.; Liu, A.; Lévesque, M. Spoils from the spoiled: Strategies for entering stigmatized markets. J. Manag. Stud. 2019, 56, 1260-1286. [CrossRef]

32. Stremersch, S.; Tellis, G.J.; Franses, P.H.; Binken, J.L. Indirect network effects in new product growth. J. Mark. 2007, 71, 52-74. [CrossRef]

33. Vedula, S.; York, J.G.; Corbett, A.C. Through the looking-glass: The impact of regional institutional logics and knowledge pool characteristics on opportunity recognition and market entry. J. Manag. Stud. 2019, 56, 1414-1451. [CrossRef]

34. Joshi, Y.V.; Reibstein, D.J.; Zhang, Z.J. Optimal Entry Timing in Markets with Social Influence. Manag. Sci. 2009, 55, 926-939. [CrossRef]

35. Fabio, C. The Role of Brand Image and Product Characteristics on Firms' Entry and OEM Decisions. Manag. Sci. 2016, 62, 3327-3350.

36. Zachary, M.A.; Gianiodis, P.T.; Payne, G.T.; Markman, G.D. Entry timing: Enduring lessons and future directions. J. Manag. 2014, 41, 1388-1415. [CrossRef]

37. Verbeke, A.; Ciravegna, L.; Lopez, L.E.; Kundu, S.K. Five configurations of opportunism in international market entry. J. Manag. Stud. 2019, 56, 1287-1313. [CrossRef]

38. Ko, S.J. The Differing Foreign Entry Mode Choices for Sales and Production Subsidiaries of Multinational Corporations in the Manufacturing Industry. Sustainability 2019, 11, 4089. [CrossRef]

39. Xie, Y.; Du, Y.-F.; Boadu, F.; Shi, X.-Y. Executives' Assessments of Evolutionary and Leapfrog Modes: An Ambidexterity Explanation Logic. Sustainability 2018, 10, 2893. [CrossRef]

40. Gu, Q.; Yang, X.; Liu, B. Pricing Decisions on Online Channel Entry for Complementary Products in a Dominant Retailer Supply Chain. Sustainability 2020, 12, 5007. [CrossRef]

41. Aldieri, L.; Vinci, C.P. Climate change and Knowledge Spillovers for Cleaner Production: New Insights. J. Clean. Prod. 2020, 271, 122729. [CrossRef]

42. Huan, W.; Jiejun, H.; Han, Z.; Chengbin, D.; Chuanglin, F. Analysis of sustainable utilization of water resources based on the improved water resources ecological footprint model: A case study of Hubei Province, China. J. Environ. Manag. 2020, 262, 110331.

43. Markman, G.; Gianiodis, P.; Payne, G.T.; Tucci, C.L. The Who, Where, What, How and When of Market Entry. J. Manag. Stud. 2019, 56, 1241-1259. [CrossRef]

44. Mcguire, T.W.; Staelin, R. An Industry Equilibrium Analysis of Downstream Vertical Integration. Mark. Sci. 2008, 27, 115-130. [CrossRef] 